\title{
Neonatal mortality and associated factors in newborn infants admitted to a Neonatal Care Unit
}

\author{
Juan C. Lona Reyes, M.D. ${ }^{a}$, René O. Pérez Ramírez, M.D. ${ }^{a}$, Leonardo Llamas Ramos, M.D. ${ }^{a}$, \\ Larissa M. Gómez Ruiz, M.D..$^{a^{*}}$, Edith A. Benítez Vázquez, M.D. ${ }^{a}$ and \\ Virginia Rodríguez Patiño, M.D. ${ }^{a}$
}

\begin{abstract}
Introduction. The increasing survival rate of preterm infants has altered the epidemiology of neonatal diseases; however, neonatal mortality is still the main component of child mortality. The objective of this study was to evaluate neonatal mortality and associated factors in newborn infants admitted to a neonatal care unit.

Material and methods. Prospective cohort study conducted between January 2016 and January 2017 at Hospital Civil de Guadalajara "Dr. Juan I. Menchaca." The incidence of deaths and associated conditions was evaluated using a multivariate logistic regression analysis.

Results. A total of 9366 live births were registered; $15 \%$ (n:1410) of these were admitted to theneonatal care unit. The mortality rate was 125.5 per 1000 hospitalized newborn infants (95\% confidence interval [CI]: 109-144); the main reasons for admission were congenital malformations or genetic disorders $(28.2 \%)$, infections $(24.9 \%)$, and respiratory distress $(20.9 \%)$. The conditions associated with death were gestational age $<37$ weeks (OR: 2.41 , 95\% CI: 1.49-3.93), birth weight $\leq 1500$ grams (OR: 6.30, 95\% CI: 4.15-9.55), moderate/severe respiratory distress at 10 minutes (OR: 1.89, 95\% CI: 1.24-2.86), Apgar score $<7$ at 5 minutes(OR:9.40,95\% CI:5.76-15.31), congenital malformations (OR: 5.52, 95\% CI: 3.12-9.78), and less than 5 antenatal care visits (OR: 1.51, 95\% CI: 1.09-2.08).

Conclusions. Preterm birth, low birth weight, respiratory distress, Apgar score $<7$, congenital malformations, and a history of $<5$ antenatal care visits were associated with a higher risk for death. Key words: perinatal mortality, child mortality, neonatal mortality, neonatal respiratory distress syndrome, preterm birth.
\end{abstract}

http:/ / dx.doi.org/10.5546/aap.2018.eng.42

To cite: Lona Reyes JC, Pérez Ramírez RO, Llamas Ramos L, et al. Neonatal mortality and associated factors in newborn infants admitted to a Neonatal Care Unit. Arch Argent Pediatr 2018;116(1):42-48.

\section{INTRODUCTION}

Millennium Development Goal 4, agreed by the United Nations member states, proposed to reduce by two thirds, between 1990 and 2015, the under-five mortality rate; ${ }^{1}$ however, a high percentage (98\%) of child mortality still takes place in developing countries and $60 \%$ of it occurs in the neonatal period. ${ }^{2-4}$

In Mexico, between 1990 and 2015, the neonatal mortality rate reduced from 11.6 deaths per 1000 live newborn infants (NBIs) to 7.07 deaths per 1000 live NBIs; however, in recent years, this indicator has remained constant and is still the main component of child mortality. ${ }^{5}$

Thanks to the implementation of strategies that have led to an increased survival among preterm patients, a variation has been observed in the epidemiology of neonatal diseases; ${ }^{6}$ for this reason, the main causes of death may be related to such epidemiological transition: neonatal respiratory distress syndrome, neonatal sepsis, intraventricular hemorrhage, and persistent pulmonary hypertension. ${ }^{78}$

It has been reported that, in addition to gestational age, other conditions that affect the risk for death are birth weight, male gender, and maternal conditions, such as age and / or level of education. ${ }^{9-}$ ${ }^{12} \mathrm{Neonatal}$ mortality surveillance helps to identify subgroups at risk that require special health care and/ or resource allocation. The objective of this study was to evaluate neonatal mortality and associated factors in NBIs admitted to a neonatal care unit.

\section{POPULATION AND METHODS}

A prospective cohort study was conducted at Hospital Civil de 
Guadalajara “Dr. Juan I. Menchaca” (HCGJIM) in the city of Guadalajara, Jalisco, Mexico. HCGJIM provides health services to an open, low-resource population. The Division of Neonatology is made up by a neonatal intensive care unit with 18 cribs and an intermediate care unit with 57 cribs. The Department of Epidemiology is responsible for recording and monitoring deaths and their causes.

The study was conducted between January $25^{\text {th }}, 2016$ and January $25^{\text {th }}, 2017$. The cohort included NBIs admitted to the Department of Neonatology; patients who were born in a different hospital facility and who were subsequently admitted to this hospital were excluded.

During the study, all infants born and hospitalized in HCGJIM were recorded; analyzed outcome measures were collected from the NBI's medical record. Studied outcome measures were sex, gestational age estimated according to Capurro's or Ballard's score, Apgar score at 5 minutes, respiratory distress score (Silverman-Anderson) at 10 minutes, congenital malformations, multiple pregnancy, maternal age, level of maternal education, marital status, number of pregnancies, risk factors, and number of antenatal care visits. Maternal risk factors were the presence of urinary tract infection, premature rupture of membranes $\geq 18$ hours, chorioamnionitis, and fever without a source of infection.

The number of deaths was obtained based on death certificates registered at the Department of Epidemiology. Patients who were admitted to and discharged from the hospital before the end of their neonatal period, upon obtaining the consent from their parents, were called at 28 days of life to corroborate survival.

Each death was allocated a basic cause and an immediate cause once the medical records and lab and specialized tests were analyzed. This assessment was done independently by three neonatologist pediatricians, and the causes were allocated if two or more of these assessments were consistent. If there was no agreement, the event was analyzed a second time.

\section{Definitions}

Basic cause of death: disease or injury that has initiated the train of morbid events leading to death. Immediate cause of death: disease directly leading to death. ${ }^{13}$ Mortality of hospitalized NBIs: deaths of patients younger than 28 days of life, born in and admitted to the neonatal care unit of HCGJIM in the study period/total number of patients born in and admitted to the neonatal care unit of HCGJIM in the study period.

\section{Statistical analysis}

Frequency and percentage were estimated as qualitative outcome measures; to establish an association with the dependent outcome measure, relative risk (RR) and 95\% confidence intervals (CIs) were introduced in the OpenEpi software (http: / / www.o penepi.com/Menu / OE_Menu.htm) using a $\chi^{2}$ test to verify the hypothesis. Median and range were estimated as quantitative outcome measures; to this end, dichotomous outcome measures were estimated using different cut-off points and analyzed as qualitative outcome measures. Out of all outcome measures, those with a $p$ value $<0.2$ were included in the multivariate logistic regression analysis using the IBM SPSS Statistics software, version 20. Conditions associated with death were analyzed based on the total number of deaths because we considered that the risk was not restricted by the NBIs' days of life. The project was approved by the Ethics and Research Committees of HCGJIM under registry no. 00079.

\section{RESULTS}

During the study period, 9366 live births were recorded; $15 \%$ (n: 1410) of them were admitted to the Department of Neonatology. Among admitted patients, $54.3 \%$ (n: 765 ) were males and $45.5 \%$ (n: 641), females; 4 patients had ambiguous genitalia.

Patients' median gestational age was 36.5 weeks (maximum: 42; minimum: 24). The gestational age was $<37$ weeks in $52.2 \%$ (n: 736) and $\leq 32$ weeks in $12.8 \%$ (n: 180). Patients' median birth weight was 2360 grams (maximum: 5380; minimum: 500). Birth weight was less than 2500 grams in $54.5 \%$ (n: 768 ) and 1500 grams or less in $17.5 \%$ (n: 247).

Besides, $63.5 \%$ (n: 895$)$ of patients were born by C-section; 8.2\% (n: 116) had an Apgar score $<7$ at 5 minutes, and 3.8\% (n: 54), an Apgar score $<5$. Respiratory distress occurred since the first 10 minutes of life in $34.3 \%$ (n: 484 ) of patients, whereas moderate/severe respiratory distress (Silverman score $>3$ ) occurred in 16\% (n: 226). Besides, 9.4\% (n: 132) of NBIs corresponded to multiple pregnancies and $7.1 \%$ (n: 100) had a congenital malformation. The median maternal age was 23 years (maximum: 45 ; minimum: 12 ); $17.9 \%$ (n: 252 ) of women were single mothers and 
$35.5 \%$ (n: 500) were primiparous.

Also, 27.8\% (n: 392) had less than 5 antenatal care visits, and $4.4 \%$ (n: 62$)$ received no antenatal care at all. In relation to education, $23.7 \%$ (n: 334) of mothers had completed only primary education and $2.9 \%$ (n: 41$)$ were illiterate.

A total of 192 deaths were registered; 15 occurred in patients older than 28 days. The mortality rate among NBIs admitted to the neonatal care unit was estimated at 125.5 events per 1000 hospitalized NBIs (95\% CI: 109-144). The incidence of death that included deaths occurring beyond the neonatal period was 136.2 events per 1000 hospitalized NBIs (95\% CI: 119-155).

In this regard, $83.3 \%$ (n: 160) of deaths occurred in patients born at $<37$ weeks of gestation; $75 \%$ (n: 120) of these, in the first week of life; mortality among preterm patients was estimated at 217.4 deaths per 1000 hospitalized NBIs. Patients with a birth weight $\leq 1500$ grams accounted for $57.3 \%$ (n: 110) of deaths; in this group, the mortality rate was 445 deaths per 1000 hospitalized NBIs, and $78.2 \%$ (n: 86) occurred in the first week of life.

During the neonatal period, respiratory distress syndrome was the basic cause of death in 20.9\% of patients; the rest were attributed to infectious processes $(24.9 \%)$, congenital malformations or genetic disorders (28.2\%), hemorrhagic disorders $(11.9 \%)$, and perinatal asphyxia (5.1\%), Table 1. Among patients who died beyond the neonatal period, late neonatal sepsis was the cause of death in $46.7 \%$ (n: 7), whereas bronchopulmonary dysplasia

TABLE 1. Causes of death among newborn infants admitted to the Neonatal Care Unit of Hospital Civil de Guadalajara "Dr. Juan I. Menchaca"

\begin{tabular}{|c|c|}
\hline & n $(\%)$ \\
\hline Congenital malformations or genetic disorders & $50(28.2)$ \\
\hline Heart malformations & 14 \\
\hline Central nervous system malformations & 11 \\
\hline Digestive tract malformations & 4 \\
\hline Skeletal dysplasias & 4 \\
\hline Edwards syndrome & 4 \\
\hline Diaphragmatic hernia & 3 \\
\hline Potter sequence & 2 \\
\hline Arthrogryposis multiplex congenita & 2 \\
\hline $\begin{array}{l}\text { Mucopolysaccharidosis type IV (1), Pierre Robin sequence (1), Patau syndrome (1), } \\
\text { pentalogy of Cantrell (1), pulmonary hypoplasia (1), epidermolysis bullosa (1) }\end{array}$ & 6 \\
\hline Respiratory diseases & $45(25.4)$ \\
\hline Respiratory distress syndrome & 37 \\
\hline Persistent pulmonary hypertension & 2 \\
\hline Apnea of prematurity & 2 \\
\hline Transient tachypnea of the newborn & 1 \\
\hline Pleural effusion (1), hydrothorax (1), pneumothorax (1) & 3 \\
\hline Infectious diseases & $44(24.9)$ \\
\hline Microbiologically-confirmed neonatal sepsis & 17 \\
\hline Necrotizing enterocolitis & 11 \\
\hline Pneumonia & 12 \\
\hline Sepsis without known isolated microorganism & 2 \\
\hline Congenital syphilis (1), antenatal varicella infection (1) & 2 \\
\hline Hemorrhagic disorders & 21 (11.9) \\
\hline Intraventricular hemorrhage & 13 \\
\hline Unborn child and newborn infant affected by abruptio placentae & 2 \\
\hline Pulmonary hemorrhage & 2 \\
\hline Disseminated intravascular coagulation & 2 \\
\hline Massive hemorrhage from the umbilical cord (1), subgaleal hematoma (1) & 2 \\
\hline Perinatal asphyxia & $9(5.1)$ \\
\hline Other & $8(4.5)$ \\
\hline Hydropsfetalis & 3 \\
\hline Extreme immaturity & 2 \\
\hline Renal failure & 1 \\
\hline Intrauterine growth restriction type III & 1 \\
\hline Gastric perforation & 1 \\
\hline Total & 177 \\
\hline
\end{tabular}


and congenital malformations caused $26.6 \%$ (n: 4), respectively.

The direct causes of death in the neonatal period were respiratory failure in $32.4 \%$ (n: 57), hypovolemic shock in $18.7 \%$ (n: 33), cardiogenic shock in $18.2 \%$ (n: 32 ), septic shock in $18.2 \%$ (n: 32 ), and mixed shock in $12.5 \%$ (n: 22); in the case of 1 patient, hyperkalemia was considered the direct cause of death. Among patients older than 28 days of life, the direct causes of death were septic shock (n: 7), cardiogenic shock (n: 5), respiratory failure (n: 2), and hypovolemic shock (n: 1).

The incidence of death based on the presence or absence of studied conditions, with RR and
95\% CI, is shown in Tables 2 and 3.

An independent multivariate analysis was done for maternal and neonatal conditions; for each, outcome measures with a $p$ value $<0.2$ were included and then excluded in a stepwise manner based on their statistical significance and influence on other outcome measures within each model. Risk factors identified in a multivariate analysis are shown in Table 4.

\section{DISCUSSION}

The mortality rate among NBIs admitted to the neonatal care unit of HCGJIM was higher than that observed at a national level (7.07/1000 live NBIs), ${ }^{5}$ given that the population seen here

TABLE 2. Incidence of deaths among newborn infants admitted to Hospital Civil de Guadalajara "Dr. Juan I. Menchaca" based on clinical and demographic characteristics, relative risk and 95\% confidence interval

\begin{tabular}{|c|c|c|c|c|c|c|}
\hline & $\begin{array}{c}\text { Number } \\
\text { of patients }\end{array}$ & $\begin{array}{l}\text { Death } \\
\text { events }\end{array}$ & $\begin{array}{c}\text { Incidence } \\
\text { per } 1000 \text { patients }\end{array}$ & $\mathbf{R R}$ & $95 \% \mathrm{CI}$ & $p$ \\
\hline \multicolumn{7}{|l|}{$\mathrm{Sex}^{*}$} \\
\hline Male & 764 & 100 & 130.9 & 0.94 & $0.72-1.23$ & 0.66 \\
\hline Female & 641 & 89 & 138.8 & & & \\
\hline \multicolumn{7}{|c|}{ Gestational age $<37$ weeks } \\
\hline Present & 736 & 160 & 217.4 & 4.6 & $3.18-6.59$ & $<0.001$ \\
\hline Absent & 674 & 32 & 47.5 & & & \\
\hline \multicolumn{7}{|c|}{ Gestational age $\leq 32$ weeks } \\
\hline Present & 180 & 87 & 483.3 & 5.7 & $4.47-7.18$ & $<0.001$ \\
\hline Absent & 1230 & 105 & 85.4 & & & \\
\hline \multicolumn{7}{|l|}{ Weight $<2500 \mathrm{~g}$} \\
\hline Present & 768 & 155 & 201.8 & 3.5 & $2.49-4.93$ & $<0.001$ \\
\hline Absent & 642 & 37 & 57.6 & & & \\
\hline \multicolumn{7}{|l|}{ Weight $\leq 1500 \mathrm{~g}$} \\
\hline Present & 247 & 110 & 445.3 & 6.3 & $4.92-8.12$ & $<0.001$ \\
\hline Absent & 1163 & 82 & 70.5 & & & \\
\hline \multicolumn{7}{|l|}{ Delivery mode } \\
\hline C-section & 895 & 127 & 141.9 & 1.1 & $0.85-1.49$ & 0.41 \\
\hline Vaginal delivery & 515 & 65 & 126.2 & & & \\
\hline \multicolumn{7}{|c|}{ Apgar score $<7$ at 5 minutes } \\
\hline Present & 116 & 66 & 569 & 5.8 & $4.65-7.35$ & $<0.001$ \\
\hline Absent & 1294 & 126 & 97.4 & & & \\
\hline \multicolumn{7}{|c|}{ Apgar score $<5$ at 5 minutes } \\
\hline Present & 54 & 35 & 648.1 & 5.6 & $4.38-7.16$ & $<0.001$ \\
\hline Absent & 1356 & 157 & 115.8 & & & \\
\hline \multicolumn{7}{|c|}{ Silverman score $\geq 1$ at 10 minutes } \\
\hline Present & 484 & 87 & 179.7 & 1.6 & $1.22-2.06$ & $<0.001$ \\
\hline Absent & 926 & 105 & 113.4 & & & \\
\hline \multicolumn{7}{|c|}{ Silverman score $>3$ at 10 minutes } \\
\hline Present & 226 & 55 & 243.3 & 2.1 & $1.59-2.78$ & $<0.001$ \\
\hline Absent & 1184 & 137 & 115.7 & & & \\
\hline \multicolumn{7}{|l|}{ Multiple pregnancy } \\
\hline Present & 132 & 25 & 189.4 & 1.4 & $0.99-2.12$ & 0.06 \\
\hline Absent & 1278 & 167 & 130.7 & & & \\
\hline \multicolumn{7}{|c|}{ Congenital malformations } \\
\hline Present & 100 & 34 & 340 & 2.8 & $2.07-3.84$ & $<0.001$ \\
\hline Absent & 1310 & 158 & 120.1 & & & \\
\hline
\end{tabular}

RR: relative risk; CI: confidence interval. * Four patients with 
had different demographic characteristics, with a high prevalence of preterm and/or very low birth weight NBIs.

In the United States, Manuck et al. ${ }^{14}$ observed that at a lower gestational age, the mortality was higher. The authors identified that the frequency of death was $44,2 \%$ among NBIs born at $<24$ weeks of gestation and less than $1 \%$ among those born at $\geq 32$ weeks. In our study, mortality was higher; its rate was $48.3 \%$ among patients born at $\leq 32$ weeks of gestation, and $13.1 \%$ among those born at 32.1-36.9 weeks.

TABLE 3. Incidence of deaths among newborn infants admitted to Hospital Civil de Guadalajara "Dr. Juan I. Menchaca" based on maternal characteristics, relative risk and 95\% confidence interval

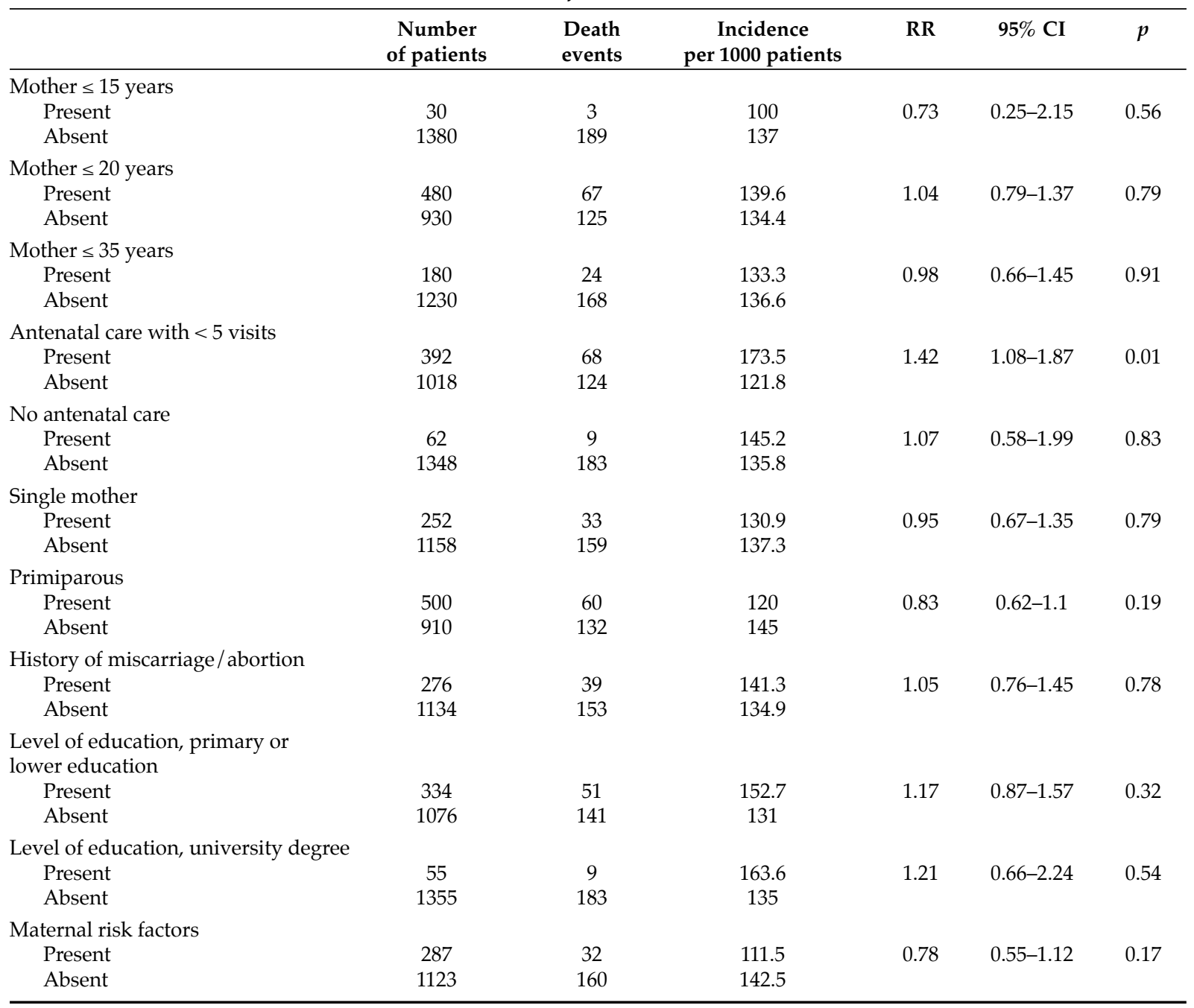

RR: relative risk; CI: confidence interval.

TABLE 4. Multivariate analysis of conditions associated with neonatal death

\begin{tabular}{|c|c|c|c|}
\hline & \multirow{2}{*}{$\begin{array}{c}\operatorname{Exp}(\mathrm{B}) \\
\text { OR }\end{array}$} & \multicolumn{2}{|c|}{$95 \% \mathrm{CI}$ for OR } \\
\hline & & Lower & Upper \\
\hline Prematurity (gestational age $<37$ weeks) & 2.41 & 1.49 & 3.93 \\
\hline Birth weight $\leq 1500$ grams $^{a}$ & 6.30 & 4.15 & 9.55 \\
\hline Moderate/severe respiratory distress ${ }^{a}$ & 1.89 & 1.24 & 2.86 \\
\hline Apgar score $<7$ at 5 minutes $^{\text {a }}$ & 9.40 & 5.76 & 15.31 \\
\hline Congenital malformations $\mathrm{s}^{\mathrm{a}}$ & 5.52 & 3.12 & 9.78 \\
\hline Less than 5 antenatal care visits ${ }^{b}$ & 1.51 & 1.09 & 2.08 \\
\hline
\end{tabular}

OR: odds ratio; CI: confidence interval. (a) Neonatal conditions; (b) Maternal conditions. 
According to the information provided by the Neocosur Neonatal Network, ${ }^{15}$ overall mortality among patients with a very low birth weight was 26\% (95\% CI: 25-26.9) and was inversely related to gestational age. Survival based on weeks of gestation ranges from $28.6 \%$ to $90.6 \%$ among NBIs born at 24-31 weeks, respectively. In the cohort of NBIs from HCGJIM, patients with a birth weight $\leq 1500$ grams had a mortality rate of 44.5\% (95\% CI: 38.4-50.7), which was higher than that reported in South American countries.

In this study, the main causes of death were congenital malformations or genetic disorders, but only $7.1 \%$ of hospitalized patients had this condition. Worldwide, the frequency of congenital anomalies is $2-3 \%$ and, in Latin American countries, such as Chile, Cuba, and Costa Rica, congenital anomalies are one of the main causes of death in the first year of life. ${ }^{16} \mathrm{In}$ Argentina, these anomalies account for $26 \%$ of infant deaths and, as a cause of death, lead over prematurity-related disorders. Similarly to our findings, Bidondo et al. ${ }^{17}$ observed that in the neonatal period, congenital anomalies accounted for a lethality rate of $18.1 \%$, with a lower risk of death among patients born at an older gestational age (OR: 0.79, 95\% CI: 0.68-0.91).

In a hospital-based study, Sônia Lansky et al. ${ }^{10}$ identified that neonatal mortality was 11.1 deaths / 1000 live births. One third of deaths were attributed to prematurity, followed by congenital malformations $(22.8 \%)$, infections $(18.5 \%)$, and asphyxia (7\%). A birth weight < 2500 grams (OR: 5.19, 95\% CI: 2.44-11.04), congenital malformations (OR: 16.55, 95\% CI: 6.47-42.38), an Apgar score $<7$ at 5 minutes (OR: 15.79, 95\% CI: 6.54-38.14), and male gender (OR: 1.49, 95\% CI: 1.08-2.05) increased the risk for death.

At HCGJIM, $83.3 \%$ of neonatal deaths occurred in preterm NBIs and the most common causes of death were congenital malformations or genetic disorders, respiratory diseases, and infections. Similarly to what has been reported by Lansky et al., ${ }^{10}$ a birth weight $\leq 1500$ grams, congenital malformations, and an Apgar score $<7$ at 5 minutes significantly increased the risk for death.

Debelew et al., ${ }^{9}$ in Ethiopia, described that neonatal mortality was 35.5/1000 live NBIs (95\% CI: 28.3-42.6). The causes of death defined through verbal autopsies were perinatal asphyxia in $47.5 \%$ of patients, neonatal infections, in $34.3 \%$, and prematurity-related conditions, in $11.1 \%$.
Conditions associated to death were $\leq 4$ antenatal care visits (OR: $0.35,95 \%$ CI: 0.18-0.68), birth at a health center (OR: 0.43,95\% CI: 0.17-0.99), gestational age < 37 weeks (OR: 2.09, 95\% CI: 1.03-4.22), obstetric complications during delivery (OR: 6.77, 95\% CI: 3.82-12.00), premature rupture of membranes $>12$ hours (OR: 7.74, 95\% CI: 2.27-26.4), and twin pregnancy (OR: 8.21, 95\% CI: 3.46-19.47).

Among patients from HCGJIM, it was observed that a maternal history of less than 5 antenatal care visits increased the probability of death by $51 \%$. A potential explanation for this finding is that an inconsistent control of pregnancy leads to missing the diagnosis of maternal or fetal comorbidities that should be managed in a timely manner.

Every year, 14 million women aged $15-19$ years get pregnant worldwide. Different studies have identified that neonatal deaths are related to adolescent pregnancy, ${ }^{3,4,10}$ and the risk is higher in the case of single mothers (OR: 3.6, $p \leq 0.01$ ), a low level of maternal education $(p \leq 0.01)$, and complications during pregnancy (OR: 2.6, $p \leq$ $0.01) .{ }^{3} \mathrm{O}$. K. Ezeh et al. identified that a small fetus (OR: 2.10, 95\% CI: 1.77-2.50), maternal age younger than 20 years (OR: $4.07,95 \% \mathrm{CI}$ : 2.83-5.86), and living in a rural area (OR: 1.26, 95\% CI: 1.03-1.55) were factors associated with neonatal mortality. ${ }^{4}$ Among patients from HCGJIM, maternal age, maternal level of education, marital status or the presence of risk factors such as urinary tract infection, premature rupture of membranes or chorioamnionitis, were not observed to increase the risk for death.

Based on the findings of this study, it is important to know and implement interventions aimed at improving survival among preterm patients, such as specialized care during pregnancy and labor, ${ }^{2,18,19}$ antenatal corticosteroid use, ${ }^{20}$ and breastfeeding in the first 24 hours, ${ }^{21}$ and to increase the resources allocated to health care. ${ }^{22,23}$

The limitations of this study are that it was conducted in a hospital sample that may be different from the general population and that the sample was too small to establish specific subgroups, such as mothers $<15$ years or who received no antenatal care at all.

\section{CONCLUSIONS}

The rate of neonatal mortality among hospitalized NBIs was 125.5 events per 1000 hospitalized NBIs and the main causes were 
congenital malformations or genetic disorders $(28.2 \%)$, infections $(24.9 \%)$, and neonatal respiratory distress syndrome (20.9\%). Prematurity, low birth weight, respiratory distress, Apgar score $<7$ at 5 minutes, congenital malformations, and a history of less than 5 antenatal care visits were associated with a higher risk of death among these patients.

\section{REFERENCES}

1. Murray CJ, Laakso T, Shibuya K, et al. Can we achieve Millenium Development Goal 4? New analysis of country trends and forecasts of under-5 mortality to 2015. Lancet 2007;370(9592):1040-54.

2. Tura G, Fantahun M, Worku A. The effect of health facility delivery on neonatal mortality: systematic review and metaanalysis. BMC Pregnancy Childbirth 2013;13:18.

3. Ramaiya A, Kiss L, Baraitser P, et al. A systematic review of risk factors for neonatal mortality in adolescent mother's in Sub Saharan Africa. BMC Res Notes 2014;7:750.

4. Ezeh OK, Agho KE, Dibley MJ, et al. Determinants of Neonatal Mortality in Nigeria: Evidence from de 2008 demographic and Health Survey. BMC Public Health 2014;14:521.

5. Instituto Nacional de Estadística y Geografía. Demografía y Población. Estadísticas de Mortalidad y Natalidad 19902015 [web site]. México, INEGI, 2017. [Accessed on: March 2017]. Available at: http://www.beta.inegi.org.mx/ proyectos/registros/vitales/mortalidad/default.html.

6. Feria-Kaiser C, Vargas MH, Furuya MEY. Cambios epidemiológicos de 1992 a 2007 en una unidad de cuidados intensivos neonatales. Gac Med Mex2013;149:5-15.

7. Miranda-Del-OlmoH, Cardiel-MarmolejoLE, Reynoso E, et al. Morbilidad y mortalidad en el RN prematurodel Hospital General de México. Rev Med Hosp Gen (Mex) 2003;66(1):22-8.

8. Pérez-Zamudio R, López-Terrones C, Rodríguez-Barboza A. Morbilidad y mortalidad del recién nacido prematuro en el Hospital General de Irapuato. Bol Med Hosp Infant Mex 2013;70(4):299-303.

9. Debelew GT, Afework MF, Yalew AW. Determinants and Causes of Neonatal Mortality in Jimma Zone, Southwest Ethiopia: A multilevel analysis of prospective follow up study. PLoS One 2014;9(9):e107184.

10. Lansky S, De Lima-Friche A, Silva A, et al. Birth in Brazil survey: neonatal mortality, pregnancy and childbirth quality of care. Cad SaudePublica2014;30(Suppl 1):S1-15.

11. Osorno-Covarrubias L, Watty-Cáceres C, Alonz-Vázquez
F, et al. Influencia de los antecedentes maternos en la mortalidad. Ginecol Obstet Mex2008;76(12):730-8.

12. Kozuki N, Lee ACC, Silvera MF, et al. The associations of parity and maternal age with small-for-gestational-age, preterm, and neonatal and infant mortality: a meta-analysis. BMC Public Health 2013;13(Suppl 3):S2.

13. Organización Panamericana de la Salud. Curso virtual sobre el correcto llenado del Certificado de Defunción. [web site]. Washington, OPS, 2014. [Accessed on: March 2015]. Available at: https://mooc.campusvirtualsp.org/ enrol/index.php?id=3.

14. Manuck TA, Rice MM, Bailit JL, et al. Preterm neonatal morbidity and mortality by gestational age: a contemporary cohort. Am J Obstet Gynecol 2016;215(1):103.e1-103.e14.

15. Fernández R, D $\square$ Apremont I, Domínguez A, et al. Supervivencia y morbilidad en recién nacido de muy bajo peso al nacer en una Red Neonatal sudamericana. Arch Argent Pediatr 2014;112(5):405-12.

16. Barboza-Arguello MP, Benavides-Lara A, Umaña L, et al. Mortalidad infantil por defectos congénitos en Costa Rica, 1981 $\square$ 2010. Rev Panam Salud Publica 2013;34(5):304-11.

17. Bidondo MP, Groisman B, Gili JA, Liascovich R, et al. Estudio de prevalencia y letalidad neonatal en pacientes con anomalías congénitas seleccionadas con datos del Registro Nacional de Anomalías Congénitas de Argentina. Arch Argent Pediatr 2015;113(4):295-302.

18. Imdad A, Mullany LC, Baqui AH, et al. The effect of umbilical cord cleansing with chlorhexidine on omphalitis and neonatal mortality in community settings in developing countries: a meta-analysis. BMC Public Health 2013;13 (Suppl 3):S15.

19. Soubeiga D, Gauvin L, Hatem MA, et al. Birth preparedness and complication readiness (BPCR) interventions to reduce maternal and neonatal mortality in developing countries: systematic review and meta-analysis. BMC Pregnancy Childbirth 2014;14:129.

20. Aleman A, Cafferata M, Gibbons L, et al. Use of antenatal corticosteroids for preterm birth in Latin America: providers knowledge, attitudes and practices. Reprod Health 2013;10:4 .

21. Debes AK, Kohli A, Walker N, et al. Time to initiation of breastfeeding and neonatal mortality: a systematic review. BMC Public Health 2013;13(Suppl 3):S19.

22. Govande V, Ballard A R, Koneru M, et al. Trends in the neonatal mortality rate in the last decade with respect to demographic factors and health care resources. Proc (Bay lUniv Med Cent) 2015;28(3):304-6.

23. Pallás Alonso CR, Arriaga Redondo M. Nuevos aspectos en torno a la prematuridad. Evid Pediatr 2008;4(2):26. 